\title{
PASSIVE FILTER DESIGN FOR POWER SUPPLY SYSTEMS WITH TRACTION LOADS
}

\author{
Valery Dovgun ${ }^{1}$, Denis Shandrygin ${ }^{1}$, Natalia Boyarskaya ${ }^{2}$ and Valentina Andyuseva ${ }^{1}$ \\ ${ }^{1}$ Siberian Federal University, 26 Kirensky St., Krasnoyarsk, 660074, Russia. \\ ${ }^{2}$ Krasnoyarsk State Agricultural University, 90 Mira prospect. Krasnoyarsk, 660049, Russia.
}

\begin{abstract}
The purpose of the investigation is to analyze resonant modes in electric power systems that feed the traction load, to study the mutual influence of the traction network and the external power supply system. Simulation model of the power supply system with traction load, implemented with the Matlab/Simulink software package, is considered. The proposed model is used to study the influence of various parameters of the power supply system on resonant modes, including the length of lines, the short-circuit power of the external power supply system, and the spectral composition of locomotive currents. It is shown that the study of resonant modes should consider the traction power supply system and the external network as a single system. Its frequency characteristics depend on both the parameters of the traction network and the parameters of the external power supply system.

The ways to improve technical characteristics of passive filtering systems (PFS) for traction railway networks due to the sustainable choice of passive filter configurations have been investigated. Different PFS that provide compensation for voltage distortions in both the traction and external network have been proposed. They provide the suppression of powerful low-frequency harmonics and the resonant mode damping in the traction network - transformer - external network system. Broadband filters of the 3-5 orders have been proposed to control the characteristics of the traction power supply system.
\end{abstract}

\section{Introduction}

Power electronic converters are the main sources of harmonic current pollution in industrial power networks. Many railway electrification systems (RES) are loaded with conventional AC thyristor-based locomotives, which produce substantial amount of third, fifth and seven harmonic currents [1-4]. Current harmonic distortions can cause overvoltage problems in the locomotive pantograph. Voltage total harmonic distortion in railway traction networks reaches $20 \ldots$ $45 \%$.

RES traction substations are supplied by three-phase $220 / 110 \mathrm{kV}$ power grid. The traction network and power grid are two coupled resonant systems with distributed parameters. Their frequency characteristics have resonance maxima, the frequencies and amplitude of which depend on length of the traction and utility networks, traction transformer impedance, etc $[1,2,5]$.

The critical factors negatively affect the traction power supply system efficiency are significant voltage drop at the end of long feeder section, current and voltage harmonics, overvoltages caused by resonant phenomena in the catenary network, and loss of average voltage $[1,3,4,6]$. Actual values of power quality parameters go beyond the existing standards in the traction network, and in some cases in the utility supply system.

The classical means of reactive power compensation and harmonic distortion attenuation in railway electrification systems are passive and active power filters. Due to their simplicity and reliability, passive filters remain the main means of distortion compensation in HV and MV networks.

In the industrial systems, passive filters have various configurations that give different compensation characteristics. The comparative analysis of the topology and characteristics of passive filters for the industrial power systems was carried out in [7, 8]. However, railway electrification systems have significant differences from industrial ones. This fact is necessary to be considered when choosing compensating devices.

Passive filters for railway electrification systems must perform the following functions $[3,4,9,10]$ :

- reactive power compensation;

- average pantograph voltage increase due to the suppression of powerful low-frequency harmonics;

- damping of resonance phenomena in the traction network and the utility supply system.

This paper investigates the harmonic resonance problems in railway electrification systems. Possibility to improve the technical characteristics of passive filters for RES due to the rational choice of filter configurations is considered. Promising filter options have been selected that provide electromagnetic compatibility of non-linear loads with traction power supply system, as well as with utility supply system.

To study the modes of power supply systems with traction loads, simulation model has been developed in MATLAB/Simulink. Using the proposed model, the mutual influence of the utility supply system parameters and the parameters of traction network have been investigated.

Traction power supply system model

Corresponding author: $\underline{\text { shandrigin2012@yandex.ru }}$ 
The structural diagram of the MATLAB/Simulink model is shown in Fig. 1. It includes $220 \mathrm{kV}$ utility supply system, a power traction transformer, $27.5 \mathrm{kV}$ traction system. The locomotive converter is modeled by shunt connected current harmonic sources.

Utility supply system is modeled by Distributed Parameter Line from Sim Power Systems library. Utility power system is assumed as a pure sinusoidal system and does not contain harmonics. The parameters of utility supply system model are given in Table 1 .

The catenary network is modeled as cascade connection of equivalent PI-type sections. Each section corresponds to the $10 \mathrm{~km}$ line and has longitudinal impedance and a shunt capacitance.

The parameters of the catenary network model are given in table II.

Table 1. Parameters of the utility supply system model

\begin{tabular}{|c|c|c|}
\hline $\mathrm{R}, \mathrm{Om} / \mathrm{Km}$ & $\mathrm{L}, \mathrm{mH} / \mathrm{Km}$ & $\mathrm{C}, \mathrm{uF} / \mathrm{Km}$ \\
\hline 0,108 & 1,3 & 0,0086 \\
\hline
\end{tabular}

Table 2. Parameters of the catenary network

\begin{tabular}{|c|c|c|}
\hline $\mathrm{R}, \mathrm{Om} / \mathrm{Km}$ & $\mathrm{L}, \mathrm{mH} / \mathrm{Km}$ & $\mathrm{C}, \mathrm{uF} / \mathrm{Km}$ \\
\hline 1,33 & 6,5 & 0,029 \\
\hline
\end{tabular}

The star-delta connected traction transformer has a rated voltage of $220 / 27.5 \mathrm{kV}$ and the rated power of 40,000 kVA;

The proposed simulation model of the railway electrification system enables to study the influence of the traction network and the utility supply system parameters, the spectral content of the electric rolling stock currents on the level of voltage distortion both in the traction system and in the utility supply system.

\section{RES frequency characteristics and harmonic modeling}

Fig. 2 shows the frequency characteristics of the traction network impedance relative to the locomotive pantograph when changing the length of the utility system from 10 to $100 \mathrm{~km}$.
The catenary network length is fixed at $30 \mathrm{~km}$.

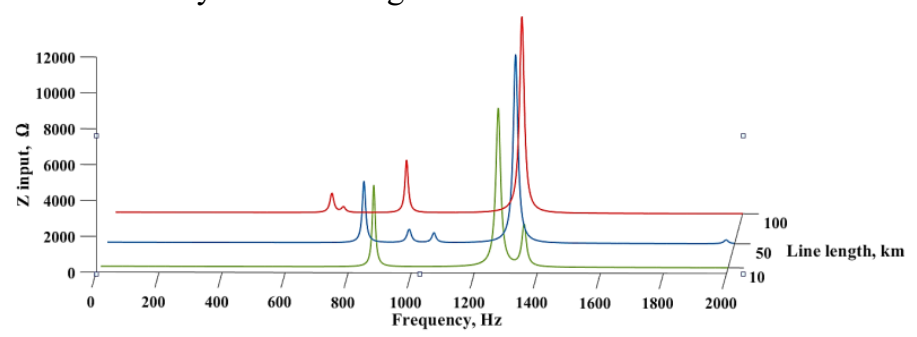

Fig. 2. Frequency characteristics of traction network impedance.

From Fig. 2 it follows that the frequency characteristics of the considered power supply system have resonance maxima in the range of $500-1000 \mathrm{~Hz}$. Resonance phenomena can cause both the traction network and $220 \mathrm{kV}$ bus voltage harmonic amplification. The maximum frequencies decrease with the increase of the $220 \mathrm{kV}$ line length. It should also be taken into account that resonance frequencies are also affected by the changes in the utility power system modes.

Typical thyristor-based locomotive current spectrum ( $\%$ of fundamental) is presented in Table 3 . In Table $3 \mathrm{~h}$ is the harmonic number.

Table 3. Locomotive current spectrum

\begin{tabular}{|c|c|c|c|c|c|c|}
\hline $\mathrm{h}$ & 3 & 5 & 7 & 9 & 11 & 13 \\
\hline$\%$ & 18,16 & 16,74 & 18,61 & 17,87 & 18,12 & 31,08 \\
\hline
\end{tabular}

Figure 3 shows the locomotive pantograph voltage spectra. The voltage spectra on the primary side of traction transformer are shown in Fig. 4. In all cases, the harmonic frequencies close to the resonant frequency of the system show significant amplification. In this context, locomotive pantograph voltage total harmonic distortion may exceed $40 \%$. Voltage total harmonic distortion on the primary side of traction transformer reaches $4.6 \%$, which exceeds the maximum permissible values determined by Russian and international standards.

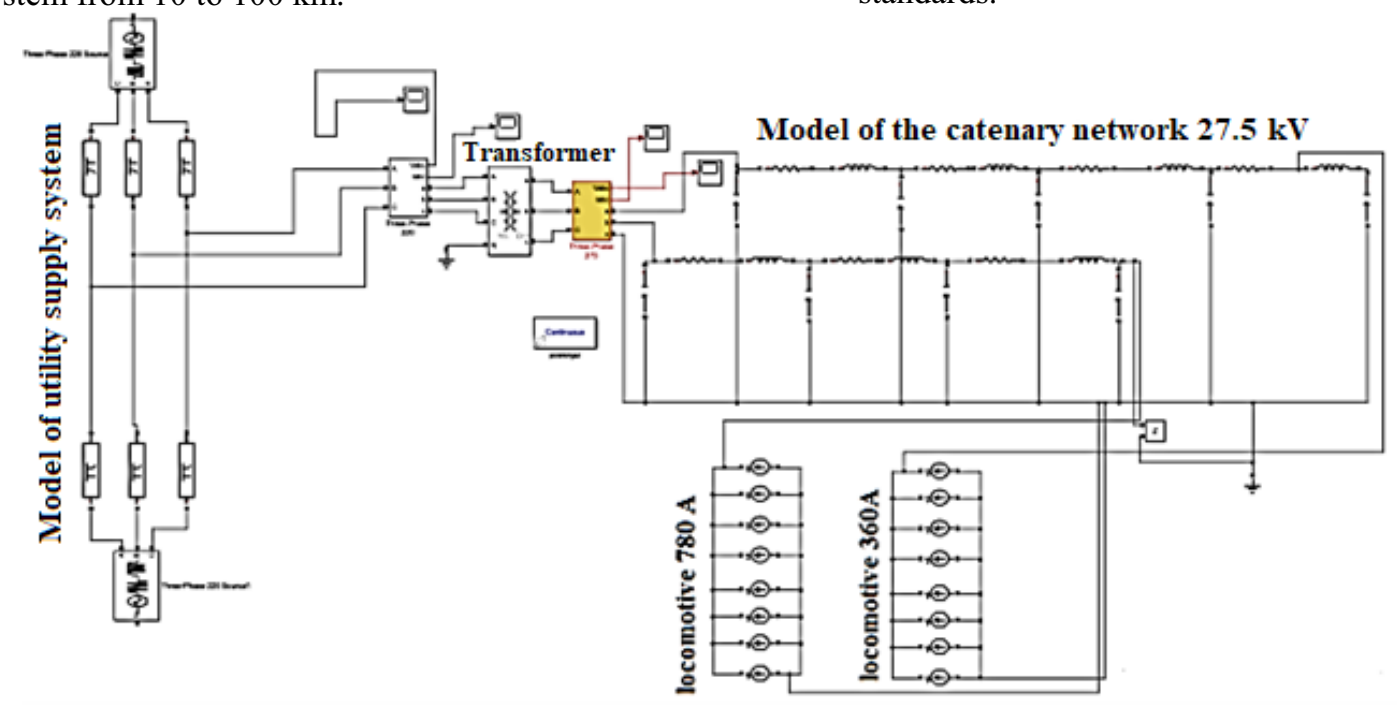

Fig.1. Simulation model of the railway electrification system 


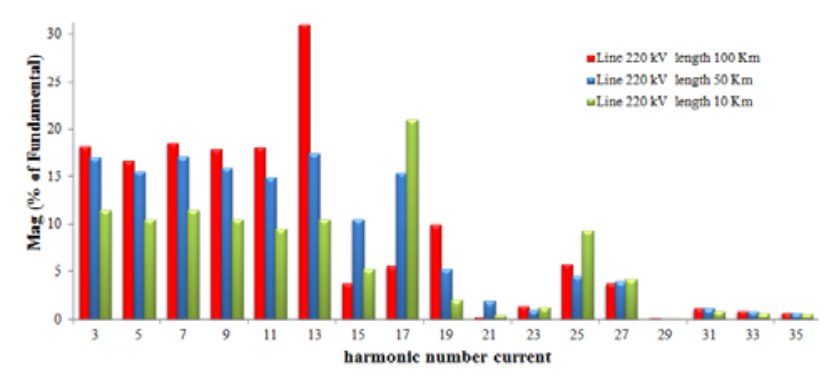

Fig.3. The voltage spectrum of the locomotive pantogaph.

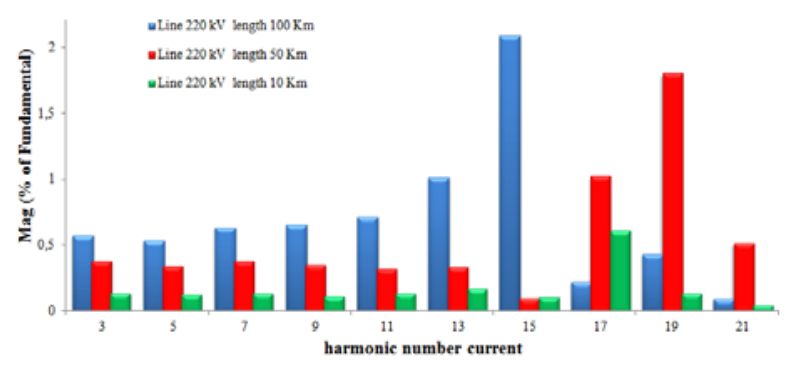

Fig. 4. Voltage spectrum on the primary side of the traction transformer

RES model simulations have shown that the utility supply system and traction network represent two coupled systems with distributed parameters. Resonance phenomena that occur in this coupled system affect both the traction network and the utility power system. Thus the key factors of the power quality normalization in the railway traction systems are the harmonic pollution mitigation and damping for harmonic resonance.

\section{Filter design for railway electrification systems}

Traditional means of reactive power compensation in AC RES feeding thyristor-based locomotives are singletuned (narrow-band) filters tuned to a resonance frequency close to $150 \mathrm{~Hz}[5,11]$. This filter includes series connected capacitor bank and a tuning reactor. In some cases, two-resonance filters are used to provide reactive power compensation and suppress the most powerful 3rd and 5th harmonics of the traction load current [10]. The disadvantage of single-tuned filters is that they suppress low-frequency harmonics but do not damp the resonance maxima of the frequency characteristics. Another disadvantage of single-tuned filters is that they form parallel resonant circuits with traction system inductance, which leads to the additional resonant modes.

In RES, it is necessary to install more efficient compensating devices, which can suppress the most powerful low-frequency voltage harmonics and reduce overvoltage due to the resonant mode damping. Such devices are needed primarily for RES that are powered by weak power systems with low fault level. It is necessary to search for new, more efficient structures of passive filters that provide electromagnetic compatibility of traction system and utility supply system.
An alternative to narrow-band resonance filter is damping broadband filter (BBF). Fig. 5 illustrates the second-order broadband filter configuration. Filter impedance is given by the following expression

$$
Z(j \omega)=R \frac{-\omega^{2}+j \omega \frac{1}{R C}+\frac{1}{L C}}{j \omega\left(j \omega+\frac{R}{L}\right)}
$$

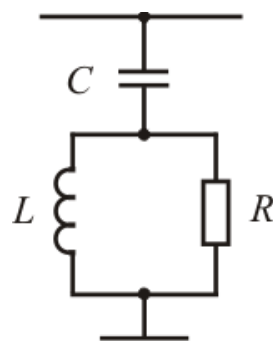

Fig. 5. Second-order broadband filter

Filter resonant frequency $\omega_{0}=1 / \sqrt{L C}$. At frequencies above $\omega_{0}$, the filter has low impedance. This provide resonance mode damping and highfrequency harmonic attenuation. The quality factor of the second order broadband filter is determined by:

$$
Q=\frac{R}{\sqrt{L / C}}
$$

For a second-order BBF, typical values of $\mathrm{Q}$ vary in the range of $0.5-5$.

The simplest broadband passive filters of the 1-2 order for RES are considered in $[2,3,12]$. The analysis conducted in $[9,10]$ showed that the use of broadband damping filters provides reducing the locomotive pantograph voltage total harmonic distortion, attenuate overvoltage due to the resonance mode damping and increase the average pantograph voltage value. Broadband filters are appropriate for randomly varying loads. The disadvantages of the simplest 1-2 order BBF are poor selectivity of the frequency characteristics and large fundamental frequency power losses.

To reduce losses, C-type broadband filters with zero fundamental frequency reactance are used $[9,13]$. In Ctype filter, an additional capacitor is connected in series with the reactor in the shunt branch (Fig. 6). The series circuit $L-C_{2}$ is tuned in resonance to the fundamental frequency. This decreases power losses in the damping resistor of the filter at the fundamental frequency.

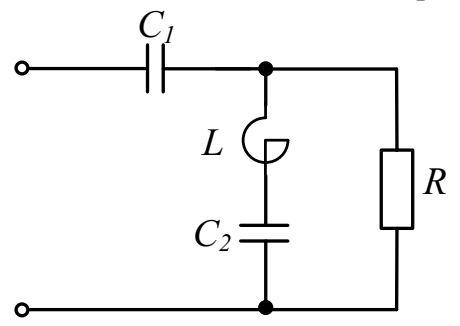

Fig. 6. C-type filter

C-type filter resonant frequency:

$$
\omega_{0}=\sqrt{\left(C_{1}+C_{2}\right) / L C_{1} C_{2}}
$$


The main advantage of C-type filter compared to second-order broadband filter Fig. 5 is lower fundamental power losses. However, this leads to the large range of capacitors. Capacitors $C_{1}$ and $C_{2}$ in the circuit (Fig. 6) are related as follows

$$
C_{2}=C_{1}\left(n^{2}-1\right)
$$

where $n$ is number of the harmonic to which the filter is tuned. The large total capacity of the passive filter in Fig. 6 significantly increases the cost of the device. In addition, fundamental power losses are achieved if the series oscillatory circuit $L-C_{2}$ is precisely tuned to the fundamental frequency. The filter fundamental frequency losses increases significantly when changing the tuning frequency caused by a variations of the shunt branch inductance or capacitance.

Another way to reduce losses at the fundamental frequency can be implemented in ladder broadband filters [14]. Third- and fifth-order broadband filters are shown in Fig. 7. This filters are single-ended ladder LC two-ports. The advantage of such structures compared to the C-type filters is significantly lower total capacitance of the capacitors. In addition, ladder filters have lower sensitivity to parameter variations.

Analytical expressions for calculating the third and higher order filters are very cumbersome and only special cases can be designed. For example, author of [15] considered the condition $\mathrm{C} 1=\mathrm{C} 2$. It is, therefore, logical to use optimization methods to determine the parameters of broadband damping filters.
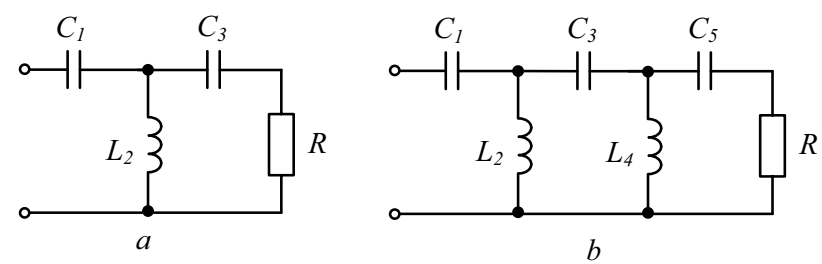

Fig. 7. 3-order broadband filter (a), 5-order broadband filter (b)

The BBF design problem is considered as an optimization problem with constraints, and may be written in the following form: find the values of the filter elements that provide a minimum of the objective function:

$\Phi(\bar{x})=\sum_{(k)} w_{k} \frac{\left|Z_{\mathrm{c}}\left(j \omega_{k}\right)\right|^{2}\left|Z_{\phi}\left(j \omega_{k}, \bar{x}\right)\right|^{2}}{\left|Z_{\phi}\left(j \omega_{k}, \bar{x}\right)+Z_{\mathrm{c}}\left(j \omega_{k}\right)\right|^{2}} J_{k}^{2}, k=1,2, \mathrm{~K}, \bar{x} \in\left\{L_{i}, C_{i}\right\}$

Subject to:

$$
\left(\operatorname{Re}\left\{\frac{1}{Z\left(j \omega_{1}, \bar{x}\right)}\right\} / \operatorname{Im}\left\{\frac{1}{Z\left(j \omega_{1}, \bar{x}\right)}\right\}\right) \leq K_{0}
$$

In the formulas (5):

$Z_{\phi}\left(\bar{x}, \omega_{k}\right)$ - input impedance of a BBF at the frequency

$\omega_{k}$;
$Z_{\mathrm{c}}\left(\omega_{k}\right)$ - impedance of the catenary network at the frequency $\omega_{k}$;

$w_{k}$ - weighting factors considering the importance of $\mathrm{k}$ term. Constant $K_{0}$ determines the maximum value of the active to reactive filter power dependence at the fundamental frequency.

Inequality $(5, b)$ determines the permissible value of the active to reactive PFS power ratio at the fundamental frequency.

Note that the proposed optimization procedure takes into account the spectrum of the current generated by the locomotive, as well as the RES frequency characteristics. The designed filter provides the minimum value of the pantograph voltage total harmonic distortion by suppressing low-frequency harmonics and the resonant mode damping.

Table 4 show the values of the BBF parameters calculated with the proposed optimization procedure. The filters reactive power is 4000 kvar.

Table 4. The element values of 3-5 order broadband filters

\begin{tabular}{|c|c|c|c|c|c|c|}
\hline$N$ & $C_{5}, \mathrm{uF}$ & $L_{2}, \mathrm{mH}$ & $C_{3}, \mathrm{uF}$ & $L_{4}, \mathrm{mH}$ & $C_{5}, \mathrm{uF}$ & $R_{\mathrm{H}}, \mathrm{Om}$ \\
\hline 3 & 8,5 & 46,6 & 4,67 & - & - & 135 \\
\hline 4 & 8,5 & 31,0 & 3,95 & 97,6 & - & 135 \\
\hline 5 & 8,5 & 35.2 & 1.89 & 56.7 & 4.1 & 135 \\
\hline
\end{tabular}

\section{Case study}

The proposed passive filtering system (PFS) consists of two sections. The low-frequency section represents a narrow-band filter tuned to a frequency close to the most powerful third harmonic $(145 \mathrm{~Hz})$. The second section is implemented by a broadband filter, which attenuates high-frequency harmonics $(h \geq 5)$ and damps resonance phenomena in the RES.

Let's consider three options for broadband filters. Filter power is the same and equals 4036 kvar

Case 1. The PFS with third-order broadband filter. BBF parameters were calculated using the proposed procedure. PFS circuit is shown in Fig. 8. The values of the filter elements are given in Table.5.

Case 2. The PFS with C-type filter. PFS circuit is shown in Fig. 9. The values of the filter elements are given in Table. 5 .

Case 3. PFS consists of two narrow - band filters tuned to $3^{\text {rd }}$ and $5^{\text {th }}$ harmonic. PFS circuit is shown Fig. 10 .

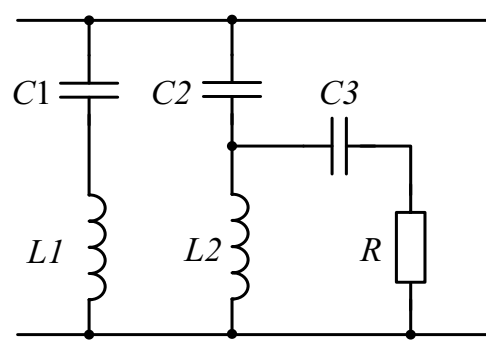

Fig. 8. PFS with 3-order BBF 
Fig. 9. PFS with C-type BBF

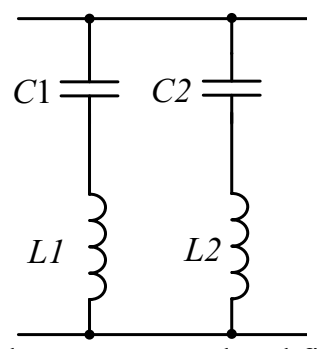

Fig. 10. PFS with two narrow - band filters

Table 5. Element values of PFS with 3-order BBF and PFS with C-type BBF

\begin{tabular}{|c|c|c|c|c|c|c|}
\hline$N$ & $C_{1}, \mathrm{uF}$ & $L_{1}, \mathrm{mH}$ & $C_{2}, \mathrm{uF}$ & $L_{2}, \mathrm{mH}$ & $C_{3}, \mathrm{uF}$ & $R_{\mathrm{H}}, \mathrm{Om}$ \\
\hline 3 & 8,5 & 141,8 & 8,5 & 38,73 & 2,2 & 135 \\
\hline $\mathrm{C}$ & 8,5 & 141,8 & 8,5 & 58 & 175 & 250 \\
\hline
\end{tabular}

The frequency characteristics of the input impedance relative to the locomotive pantograph after the installation of compensating devices are shown in Fig.11.

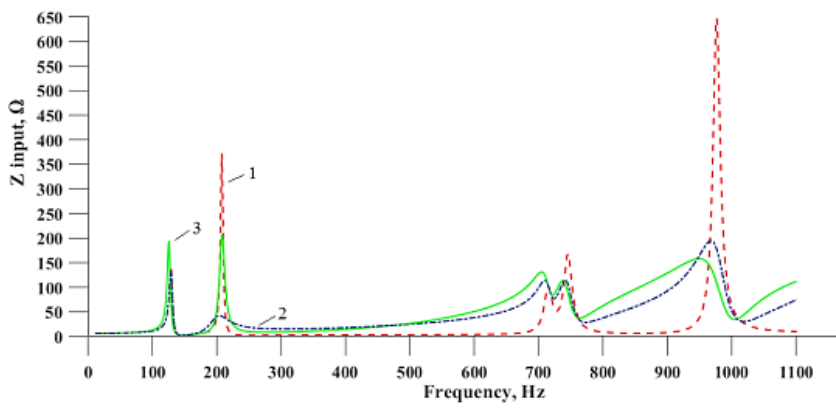

Fig. 11. Frequency characteristics of the RES input impedance after the installation of compensating devices: 1- PFS with two narrow - band filters, 2-PFS with C-type BBF, 3- PFS with 3-order BBF

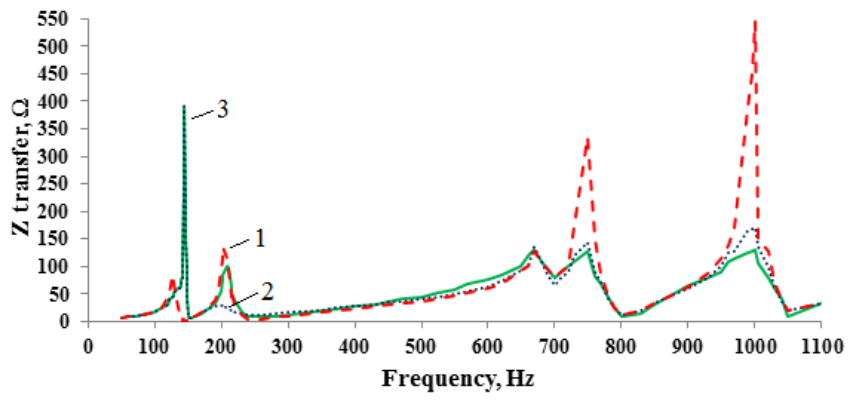

Fig. 12 Frequency characteristics of the RES transfer impedance after the installation of compensating devices: 1PFS with two narrow - band filters, 2-PFS with C-type BBF, 3- PFS with 3-order BBF.

Figure 13 shows the locomotive pantograph spectra after the installation of compensating devices.

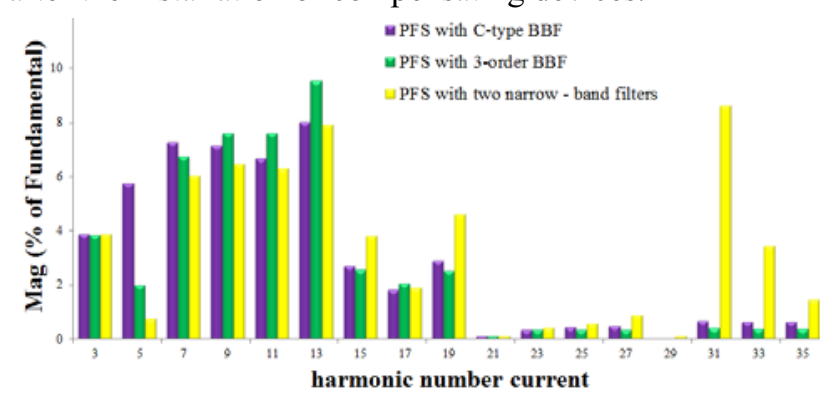

Fig. 13. Voltage spectrum on the primary side of the traction transformer.

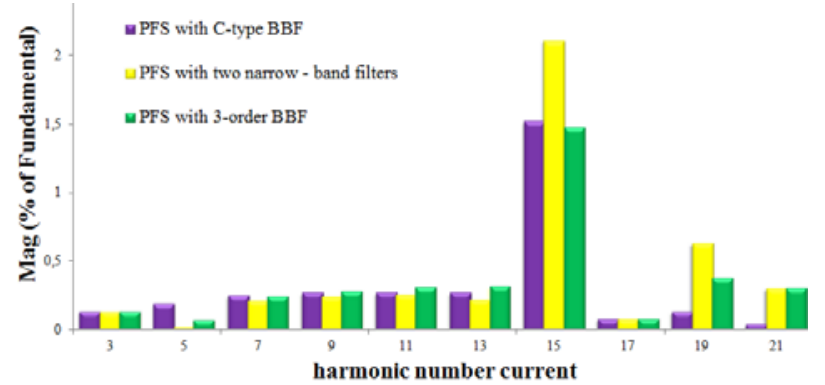

Fig. 14. Voltage spectrum on the primary side of the traction transformer.

Table 6 shows the values of the harmonic voltage coefficients when after the installation of compensating devices.

Table 6. The values of the harmonic coefficients $27,5 \mathrm{kV}, \%$

\begin{tabular}{|c|c|c|c|c|c|c|c|c|}
\hline \multirow{2}{*}{ Filter option } & \multicolumn{7}{|c|}{ The values of the harmonic coefficients $27,5 \mathrm{kV}, \%$} \\
\cline { 2 - 10 } & $\mathrm{K}_{\mathrm{U}(3)}$ & $\mathrm{K}_{\mathrm{U}(5)}$ & $\mathrm{K}_{\mathrm{U}(7)}$ & $\mathrm{K}_{\mathrm{U}(9)}$ & $\mathrm{K}_{\mathrm{U}(11)}$ & $\mathrm{K}_{\mathrm{U}(13)}$ & $\mathrm{K}_{\mathrm{U}(15)}$ & $\mathrm{K}_{\mathrm{U}}$ \\
\hline Without PFS & 18,16 & 16,74 & 18,61 & 17,87 & 18,12 & 31,08 & 3,87 & 52,64 \\
\hline PFS with C-type BBF & 3,88 & 5,76 & 7,28 & 7,16 & 6,69 & 8,02 & 2,71 & 16,82 \\
\hline $\begin{array}{c}\text { PFS with two narrow - } \\
\text { band filters }\end{array}$ & 3,88 & 0,76 & 6,05 & 6,49 & 6,30 & 7,93 & 3,82 & 18,11 \\
\hline PFS with 3-order BBF & 3,86 & 2,01 & 6,75 & 7,61 & 7,63 & 9,54 & 2,59 & 17,03 \\
\hline
\end{tabular}


Table 7. The values of the voltage harmonic coefficients on the primary side of the traction transformer $220 \mathrm{kV}, \%$

\begin{tabular}{|c|c|c|c|c|c|c|c|c|}
\hline \multirow{2}{*}{ Filter option } & \multicolumn{7}{|c|}{ The values of the harmonic coefficients $220 \times \mathrm{V}, \%$} \\
\cline { 2 - 10 } & $\mathrm{K}_{\mathrm{U}(3)}$ & $\mathrm{K}_{\mathrm{U}(5)}$ & $\mathrm{K}_{\mathrm{U}(7)}$ & $\mathrm{K}_{\mathrm{U}(9)}$ & $\mathrm{K}_{\mathrm{U}(1)}$ & $\mathrm{K}_{\mathrm{U}(13)}$ & $\mathrm{K}_{\mathrm{U}(15)}$ & $\mathrm{K}_{\mathrm{U}}$ \\
\hline Without PFS & 1,16 & 1,17 & 1,49 & 1,78 & 2,57 & 8,94 & 1,83 & 10,4 \\
\hline PFS with C-type BBF & 0,13 & 0,19 & 0,25 & 0,27 & 0,27 & 0,27 & 1,52 & 1,64 \\
\hline $\begin{array}{c}\text { PFS with two narrow - } \\
\text { band filters }\end{array}$ & 0,13 & 0,02 & 0,21 & 0,24 & 0,26 & 0,22 & 2,11 & 2,18 \\
\hline PFS with 3rd-order BBF & 0,13 & 0,07 & 0,24 & 0,28 & 0,31 & 0,32 & 1,47 & 1,59 \\
\hline
\end{tabular}

Comparison of the analysis results shows that PFS with broadband damping filters provide more effective voltage harmonic attenuation in the frequency range exceeding 250 Hz. Due to this, the negative impact of railway traction system on wired communication devices and signaling system is reduced.

\section{Conclusion}

In this paper power quality problems of railway electrification systems are considered. In is shown that railway traction network and external grid are coupled resonance systems. A passive filtering system for harmonic mitigation and resonance damping in RES is considered. System consists of parallel connection narrow-band third harmonic filter and a broadband section. The method for design of arbitrary order broadband filters is proposed. The proposed filtering system is effective for harmonic mitigation and resonance damping.

Modeling showed that PFS with the 3-5 order broadband filters have significant technical advantages over devices based on narrow-band sections and simple damping circuits. The proposed PFS provides more effective high-frequency voltage harmonic attenuation, has lower losses at the fundamental frequency and lower total capacitance.

\section{References}

1. Hu H., Shao Y., Ma J., He Z., Gao S. Overview of harmonic and resonance in railway electrification systems. IEEE trans. on Industry Applications, Vol. 54, 2018, No. 5, pp. 5227-5245.

2. Tan P.-C., Loh P., Holmes D., Optimal impedance termination of $25-\mathrm{kV}$ electrified railway systems for improved power quality. - IEEE Trans. on Power Delivery, 2005, Vol. 20, No. 2, pp. 1703-1710.

3. Tan P-C., Morrison R. E., Holmes D. Voltage form factor control and reactive power compensation in a $25-\mathrm{kV}$ electrified railway system using a shunt active filter based on voltage detection. - IEEE trans. on Industry Applications, Vol. 39, 2003, No. 2, pp. 575581.

4. S. M. Mousavi, Gazafrudi, A Tabakhpour Langerudy, E. F. Fuchs, K. Al-Haddad. Power Quality Issues in Railway Electrification: A Comprehensive Perspective, IEEE Transactions on Industrial Electronics, vol. 62, no. 5, pp. 3080-3090, 2015. doi: 10.1109/TIE.2014.2386794.
5. Shandrygin DA, Dovgun VP, Egorov DE, Manshin MV. An analysis of resonant modes in electric power systems with a traction load. Vestnik Irkutskogo gosudarstvennogo tehnicheskogo universiteta = Proceedings of Irkutsk State Technical University. 2020; 24(2):396-407. (In Russ.) https://doi.org/10.21285/1814-3520-2020-2-396-407/

6. Wang J., Li H., Feng L., Xu L. Analysis of power quality issues of electrified railway. $20178^{\text {th }}$ International Conference on Mechanical and Intelligent Manufacturing technologies (ICMIMT). Pp. 179-182.

7. Das J. Passive filters - potentialities and limitations. - IEEE trans. on industry applications. Vol. 40, No. 1, January/February, 2004, pp. 232-241.

8. Nassif A., Xu W., Freitas W. An investigation on the selection of filter topologies for passive filter applications. - IEEE trans. on Power Delivery, Vol. 24, 2009, No. 3, pp. 1710-1718.

9. Hu H., He Z., Gao S. Passive filter design for China high-speed railway with considering harmonic resonance and characteristic harmonics. - IEEE Trans. on Power Delivery, Vol. 30, 2015, No. 1, pp. 505-514.

10. Nikolaev I., Stashkov I., Sinjagovsky A., Dovgun V. Synthesis of Wideband Damping Filter for Electric Traction Systems, Journal of Siberian Federal University. Engineering, 2016, № 1. pp. 61-70.

11. Morrison R. E., Barlow M. J. Continuous overvoltage on A.C. traction systems. IEEE Transactions on power apparatus and systems, Vol. PAS-102, No. 5, 1983, pp. 1211-1217.

12. Morrison R. E. Power quality issues on AC traction systems. - Conf. rec. $9^{\text {th }}$ international conf. Harmonics and quality of power, 2000, pp. 709-714.

13. Arrillaga J. et al., Power System Harmonic Analysis. Hoboken, NJ, USA: Wiley, 1997.

14. Xiao Y. The method for designing the third order filter. - Proc. $8^{\text {th }}$ IEEE Int. Conf. Harmonics and Quality of Power, Oct. 1998, pp. 139-142.

15. Dovgun V., Egorov D., Novikov V., Zvyagintsev E. Parametric synthesis of broadband power harmonic filters. Electrichestvo, 2018, No. 12, pp. 14-21. 